\title{
CONGRESSOS
E CONFERÊNCIAS
NO ESTRANGEIRO \\ CONGRESSOS
E CONFERÊNCIAS
NO ESTRANGEIRO \\ CONGRESSOS
E CONFERÊNCIAS
NO ESTRANGEIRO
}

Para informação adicional contactar a sede da S.P.Q.,

Av. da República, $37-4 .^{\circ}-1000$ LISBOA - Telef. 734637.

\begin{tabular}{|c|c|c|}
\hline \multicolumn{3}{|l|}{1983} \\
\hline \multicolumn{3}{|c|}{ Outubro } \\
\hline $4-8$ & $\begin{array}{l}\text { Dubrovnik } \\
\text { (Iugoslávia) }\end{array}$ & $\begin{array}{l}\text { 4th International Meeting on Radiation } \\
\text { Processing }\end{array}$ \\
\hline $5-6$ & $\begin{array}{l}\text { Niagara F. } \\
\text { (Ont. Canadá) }\end{array}$ & $\begin{array}{l}\text { 3rd Symposium on Environmental Pol- } \\
\text { lution }\end{array}$ \\
\hline $7-8$ & $\begin{array}{l}\text { Niagara F. } \\
\text { (Ont. Canadá) }\end{array}$ & $\begin{array}{l}\text { 3rd Int. Chromatography / Spectro- } \\
\text { scopy Conference }\end{array}$ \\
\hline $7-8$ & $\begin{array}{l}\text { Le Mans } \\
\text { (França) }\end{array}$ & $\begin{array}{l}\text { 8e Colloque national français de } \\
\text { Chromatographie d'exclusion (GPC) }\end{array}$ \\
\hline $11-13$ & $\begin{array}{l}\text { Pointe à Pitre } \\
\text { (Guadaloupe) }\end{array}$ & $\begin{array}{l}2 e \text { Conférence Internationale sur les } \\
\text { Usines flottantes }\end{array}$ \\
\hline $25-28$ & $\begin{array}{l}\text { Tokyo } \\
\text { (Japão) }\end{array}$ & $\begin{array}{l}\text { 4e Conférence Internationale sur les } \\
\text { Matériax Composites }\end{array}$ \\
\hline $27-28$ & $\begin{array}{l}\text { Londres } \\
\text { (G.-B.) }\end{array}$ & $\begin{array}{l}\text { Discussion Meeting on the Physics } \\
\text { Chemistry and Applications of Liquid } \\
\text { Crystals }\end{array}$ \\
\hline
\end{tabular}

\begin{tabular}{|c|c|c|}
\hline \multicolumn{3}{|c|}{ Novembro } \\
\hline $3-5$ & $\begin{array}{l}\text { Vienne } \\
\text { (Áustria) }\end{array}$ & $\begin{array}{l}\text { 11. Kolloquium über Metallkundliche } \\
\text { Analyse }\end{array}$ \\
\hline $8-10$ & $\begin{array}{l}\text { Paris } \\
\text { (França) }\end{array}$ & $\begin{array}{l}\text { Ile Colloque Européen sur le Récupé- } \\
\text { ration assistée du pétrole }\end{array}$ \\
\hline $15-19$ & $\begin{array}{l}\text { Budapest } \\
\text { (Hungria) }\end{array}$ & $\begin{array}{l}\text { International Conference on Cometary } \\
\text { Exploration }\end{array}$ \\
\hline $17-19$ & $\begin{array}{l}\text { Rueil-Malmai- } \\
\text { son (França) }\end{array}$ & $\begin{array}{l}\text { Colloque "Les polymères organiques } \\
\text { utilisables à température élevée et leurs } \\
\text { applications" }\end{array}$ \\
\hline $22-24$ & $\begin{array}{l}\text { Montplellier } \\
\text { (França) }\end{array}$ & $\begin{array}{l}\text { Colloque National du GFP "Poly- } \\
\text { mères spéciaux" }\end{array}$ \\
\hline \multicolumn{3}{|l|}{1984} \\
\hline \multicolumn{3}{|l|}{ Abril } \\
\hline $10-13$ & $\begin{array}{l}\text { München } \\
\text { (R.F.A.) }\end{array}$ & $\begin{array}{l}\text { Analytica } 84 \text { (9th International Exhibi- } \\
\text { tion with International Conference } \\
\text { Biochemische Analytik } 84 \text { ) }\end{array}$ \\
\hline \multicolumn{3}{|c|}{ Setembro } \\
\hline $3-6$ & $\begin{array}{l}\text { Viana } \\
\text { do Castelo } \\
\text { (Portugal) }\end{array}$ & $\begin{array}{l}15 .^{\circ} \text { Congresso dos Químicos Teóricos } \\
\text { de Expressão Latina }\end{array}$ \\
\hline \multicolumn{3}{|l|}{ Julho } \\
\hline $16-21$ & $\begin{array}{l}\text { Lisboa } \\
\text { (Portugal) }\end{array}$ & $\begin{array}{l}\text { IX Simpósio Ibero-Americano } \\
\text { de Catálise }\end{array}$ \\
\hline
\end{tabular}

\section{COLABORE COM A SOCIEDADE}

